\title{
Artificial Intelligence Control Applied in Wind Energy Conversion System
}

\author{
Arama Fatima Zohra ${ }^{1}$, Bousserhane Ismail Khalil ${ }^{2}$, Laribi Slimane ${ }^{3}$, Sahli Youcef ${ }^{4}$, Mazari Benyounes ${ }^{5}$ \\ ${ }^{1,2}$ Department of Electrical and Computer Engineering, University of Béchar Bp 417, Algeria \\ ${ }^{1}$ Department of Technical Sciences, University of d'ADRAR, Algeria \\ ${ }^{3,4}$ Unité de Recherche en Energies Renouvelables en Milieu Saharien, URERMS, Centre de Développement des Energies \\ Renouvelables, CDER, 01000, ADRAR, Algéria \\ ${ }^{5}$ University of Science and Technology Mohamed Boudiaf, Aljazair
}

\begin{tabular}{l} 
Article Info \\
\hline Article history: \\
Received Jan 4, 2018 \\
Revised Mar 9, 2018 \\
Accepted Mar 23, 2018 \\
\hline Keyword: \\
Doubly fed induction \\
Field oriented control \\
Generator PI regulator \\
The neural network regulator \\
Wind energy conversion system
\end{tabular}

\begin{abstract}
The objective of this paper is to study the dynamic response of the wind energy conversion system (WECS) based on the Doubly Fed Induction Generator (DFIG). The DFIG rotor is connected to the grid via a converter. The active and reactive power control is realized by the DFIG rotor variables control, using the field oriented control (FOC). The vector control of DFIG is applied by the use of tow regulators PI and the neural network regulator (NN). The generator mathematical model is implemented in Matlab/ Simulink software to simulate a DFIG of $1.5 \mathrm{MW}$ in order to show the efficiency of the performances and robustness of the studied control systems. The simulation obtained results shows that the robustness and response time of the neural network regulator is better than those obtained by the PI classical regulator.
\end{abstract}

\section{Copyright $(2018$ Institute of Advanced Engineering and Science.} All rights reserved.

\section{Corresponding Author:}

Arama Fatima Zohra,

Department of Electrical and Computer Engineering,

University of Béchar Bp 417, Algeria

Email: fatimaarama@yahoo.fr

\section{INTRODUCTION}

Wind power is one of the renewable energies which has a use growth in the world due to clean and non-polluting nature of this technology [1] [2]. Several machines were used in WECS, but the range of wind speed was limited in classical machines, the advanced technology created DFIG which solves this problem and makes these systems more powerful. Several control methods of the DFIG are appeared, among them, the vector control [3]. The principle of this control is to make DFIG similar to separate excitation DC machine.

Zerzouri et al. [4] have tried to improve the performance of a DFIG wind energy conversion system, they have proposed the vector control with the PI controller to decouple the active and reactive power of the stator. They have used a single PI in each control loop, but this control has oscillations, exceedances, and the decoupling is not fully maintained. Poitiers et al. [5] have used the RST polynomial controller, they have found that the RST control is more robust than the PI control compared to the rotor resistance variation, but the oscillations remain apparent.

Hamane et al. [6] have investigated the decoupling control of active and reactive DFIG powers by the Sliding Mode (SM) regulator which shows superiority over PI during robustness testing, but this method had a slow response time. Viswanadha et al. [7] have commanded the DFIG by two methods; the DPC command and the power transfer matrix model, they have concluded that the power transfer matrix method has a better result than the DPC command. Giannakis et al. [8] have presented a study of the decoupled 
control of P-Q without mechanical sensor for DFIG-based WECS with intelligent controllers. They are focused on the implementation of fuzzy logic controllers combined with conventional PI for the adjustment of active and reactive power.

In these last years, a big interest is given to the use of neural network in identification and control of the nonlinear systems [9] [10]; this is mainly due to their capacities of training and generalization. Mishra et al [9] have developed an indirect vector control by implementing intelligent controllers (Fuzzy and Neural netwerk) to control the speed of an induction motor (IM), they have concluded that the controller based on the neural network has a more robust than the PI and fuzzy logic controllers.

This paper presents a comparison between the WECS performance using PI and NN controllers. The PI regulator is simple and easy in implementation and gives acceptable performances, but it hasn't robustness in case of parameter variations. The neural network controller is proved to be an interesting method for the design of controllers and applied in many fields because of its excellent properties, such as insensitivity to external disturbances and parameter variations, It can present also fast dynamic responses if the switching devices support a high frequency. The studied system is presented in (Figure 1).

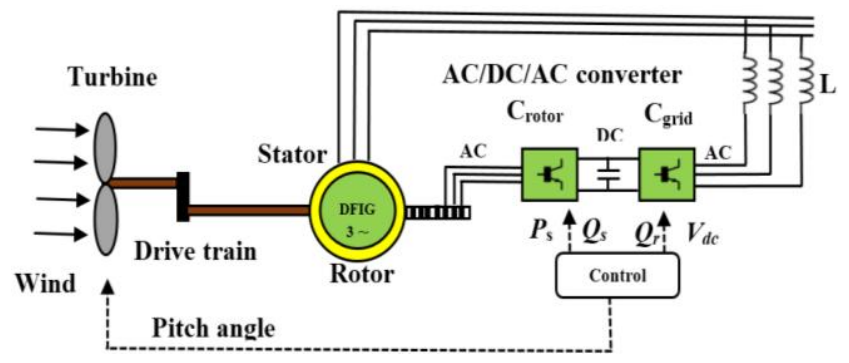

Figure 1. Diagram of the studied system

\section{MODELING AND CONTROL OF DFIG}

\subsection{DFIG modeling}

The Park transformation of the DFIG electrical equations gives the following equations [11]-[14]:

$$
\left\{\begin{array}{l}
V_{s d}=R_{s} i_{s d}+\frac{d \Phi_{s d}}{d t}-\omega_{s} \Phi_{s q} \\
V_{s q}=R_{s} i_{s q}+\frac{d \Phi_{s q}}{d t}+\omega_{s} \Phi_{s d} \\
V_{r d}=R_{r} i_{r d}+\frac{d \Phi_{r d}}{d t}-\omega_{r} \Phi_{r q} \\
V_{r q}=R_{r} i_{r q}+\frac{d \Phi_{r q}}{d t}+\omega_{r} \Phi_{r d}
\end{array}\right.
$$

The fields are given by:

$$
\left\{\begin{array}{l}
\Phi_{s d}=L_{s} i_{s d}+M_{s r} i r d \\
\Phi_{s q}=L_{s} i_{s q}+M_{s r} i r q \\
\Phi_{r d}=L_{r} i_{r d}+M_{s r}{ }^{i} s d \\
\Phi_{r q}=L_{r} i_{r q}+M_{s r}{ }^{i} s q
\end{array}\right.
$$

The electromagnetic torque is given by:

$$
\begin{gathered}
C_{e m}=P \frac{M_{s_{r}}}{L_{s}}\left(\Phi_{s q} i_{r d}-\Phi_{s d^{i} r q}\right) \\
J \frac{d \Omega_{m e c}}{d t}=C_{e m}-C_{r}-f . \Omega_{m e c}
\end{gathered}
$$




\subsection{Power control}

To easily control the electrical power produced by the DFIG, an independent control of the active and reactive powers is applied by FOC of stator. The principle of this method consists in aligning stator field along the $\mathrm{d}$ axis of Park reference frame in order to eliminate the coupling between the powers. (Figure 2) [3] [15]. We have a quadratic stator flux null ( $\Phi_{s q}=0$ ), then the direct stator flux is given by $\Phi s d=\Phi s$. The equation systems (1) and (2) can be simplified as the following form:

$$
\left\{\begin{array}{c}
V_{s d}=R_{s} i_{s d} \\
V_{s q}=R_{s} i_{s q}+\omega_{s} \Phi_{s} \\
V_{r d}=R_{r} i_{r d}+\frac{d \Phi_{r d}}{d t}-\omega_{r} \Phi_{r q} \\
V_{r q}=R_{r} i_{r q}+\frac{d \Phi_{r q}}{d t}+\omega_{r} \Phi_{r d}
\end{array}\right.
$$

For the high power machines, the resistance of the stator windings are neglected. Equation 6.

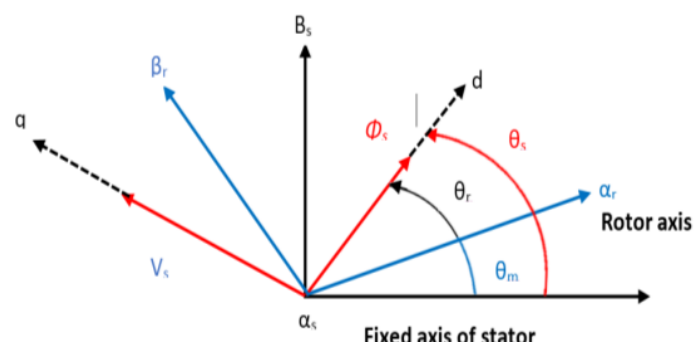

Figure 2. Position of the stator flux [16] [17].

$$
\begin{aligned}
& \left\{\begin{array}{c}
V_{s d}=0 \\
V_{s q}=V_{s}=\omega_{s} \Phi_{s} \\
V_{r d}=R_{r} i_{r d}+\frac{d \Phi}{d t}-\omega_{r} \Phi_{r q} \\
V_{r q}=R_{r} i_{r q}+\frac{d \Phi}{d t}+\omega_{r} \Phi_{r d}
\end{array}\right. \\
& \left\{\begin{array}{c}
\Phi_{s}=L_{s}{ }^{i} s d^{+M}{ }^{i} r^{i} r d \\
0=L{ }_{s}{ }^{i}+M{ }^{i} r^{r} r q \\
\Phi_{r d}=L_{r}{ }^{i} r d^{+}{ }^{i} r^{i} s d \\
\Phi_{r q}=L_{r}{ }^{i} r q+M{ }^{i} r^{i} s q
\end{array}\right. \\
& C e m=-P \frac{M s r}{L s} \Phi s \text { irq }
\end{aligned}
$$

The active and reactive stator power in the Park reference, are written as:

$$
\left\{\begin{array}{l}
P=v_{s d}{ }^{i} s d^{+v_{s q}}{ }^{i} s q \\
Q=v_{s q}{ }^{i} s d^{-v_{s d} i}{ }^{i} s q
\end{array}\right.
$$

According to FOC, the equation systems (9) can be simplified as:

$$
\begin{aligned}
& \left\{\begin{array}{l}
P=v{ }_{s} \text { s } \\
Q=v{ }^{i} \text { sd }
\end{array}\right. \\
& \left\{\begin{array}{c}
i_{s d}=\frac{V_{s}}{\omega_{s} L_{s}}-\frac{M s r}{L_{s}} \cdot i_{r d} \\
i_{s q}=-\frac{M s r}{L_{s}} \cdot i_{r q}
\end{array}\right.
\end{aligned}
$$




$$
\begin{aligned}
& P=-\frac{V_{s} M_{s r}}{L_{s}} i_{r q} \\
& Q=-\frac{V_{s} M_{s r}}{L_{s}} i_{r d}+\frac{V_{s}^{2}}{L_{s}{ }_{s}} \\
& \left\{\Phi_{r d}=\left(L_{r}-\frac{M_{s r}^{2}}{L_{s}}\right) i_{r d}+\frac{M_{s r} V_{s}}{\omega_{s} L_{s}}\right. \\
& \Phi_{r q}=\left(L_{r}-\frac{M_{s r}^{2}}{L_{s}}\right) i_{r q} \\
& V_{r d}=R_{r} i_{r d}+\left(L_{r}-\frac{M_{s r}^{2}}{L_{s}}\right) \frac{d i_{r d}}{d t}-g \omega_{s}\left(L_{r}-\frac{M_{s r}^{2}}{L_{s}}\right) i_{r q} \\
& V_{r q}=R_{r} i_{r q}+\left(L_{r}-\frac{M_{s r}^{2}}{L_{s}}\right) \frac{d i_{r q}}{d t}+g \omega_{s}\left(L_{r}-\frac{M_{s r}^{2}}{L_{s}}\right) i_{r d}+g \frac{M_{s r} V_{s}}{L_{s}}
\end{aligned}
$$

\subsection{Control of active and reactive powers of DFIG}

The decoupling of the active and reactive powers is due to voltages and currents which are evaluated using transient equations of the machine [18]. This method is favored with microprocessors, but it is very sensitive to parameter variations of the machine. The voltages are calculated using the power equation.

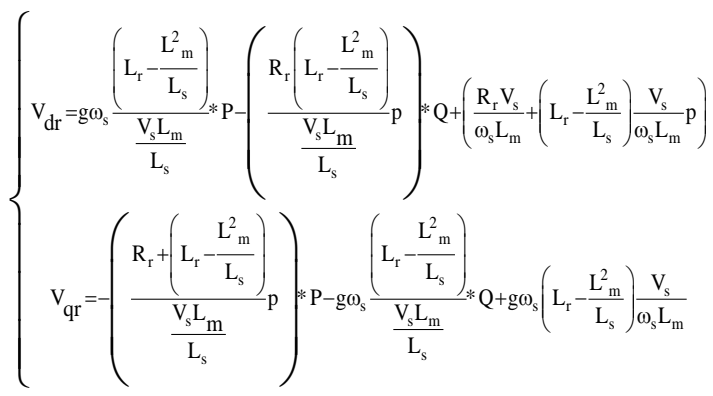

In this used method, the power is controlled using two cascade controllers, the first is the power controller and the second is the current controller. Figure 3.

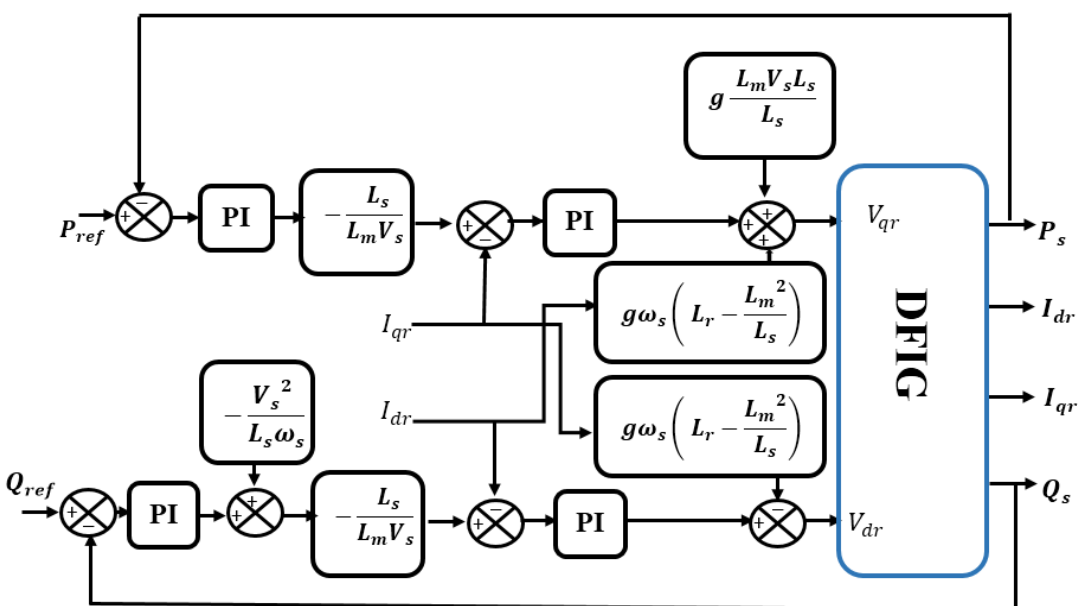

Figure 3. Control diagram of DFIG. 


\section{NEURAL NETWORK CONTROL}

The use of an analogical controller leads to the performance degradation in nonlinear and several processes [19], [10]. Many intelligent control methods have been applied on DFIG as fuzzy control, neural networks [20], [10].

The use of neural networks is a technique for controlling complex systems can be justified by its simplicity of implementation (preliminary mathematical analysis) [21], [10]. In this work, we consider the process as a black box that has the ability to control the minimum of process informations. The idea is to replace the four PI regulators of FOC by neural regulators (NN) simple. For the training of the neural weights from PI regulators, we use an algorithm of back-propagation called the algorithm of Levenberg-Marquardt (LM) [22] [23].

Each neural network has a function that is well defined depending on selected architecture (hidden layers number and neural number in each hidden layer). The problem is to find the NN regulator that gives the better results. In our case, we take a structure of neural network with only one hidden layer that containing three neurons using the sigmoid transfer function (Figure 4).

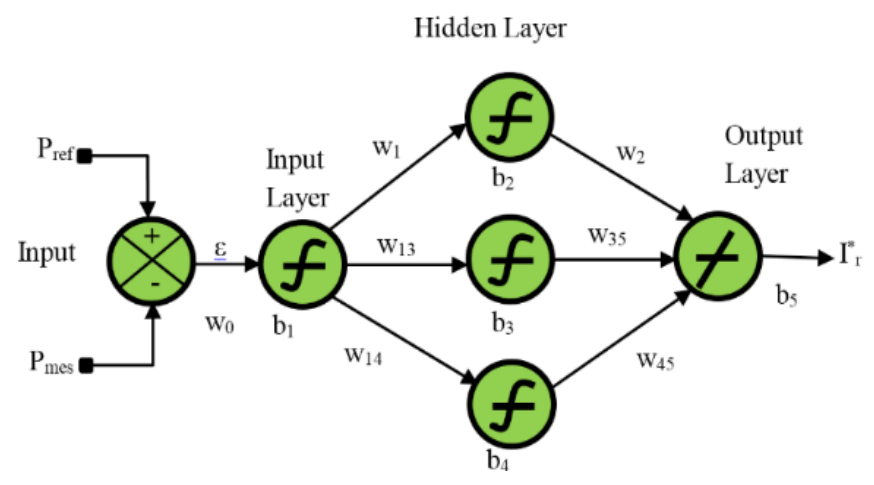

Figure 4. Configuration of the multilevel perceptrons: (1-3-1).

The global diagram of FOC control with neural network regulators is presented in (Figure 5).

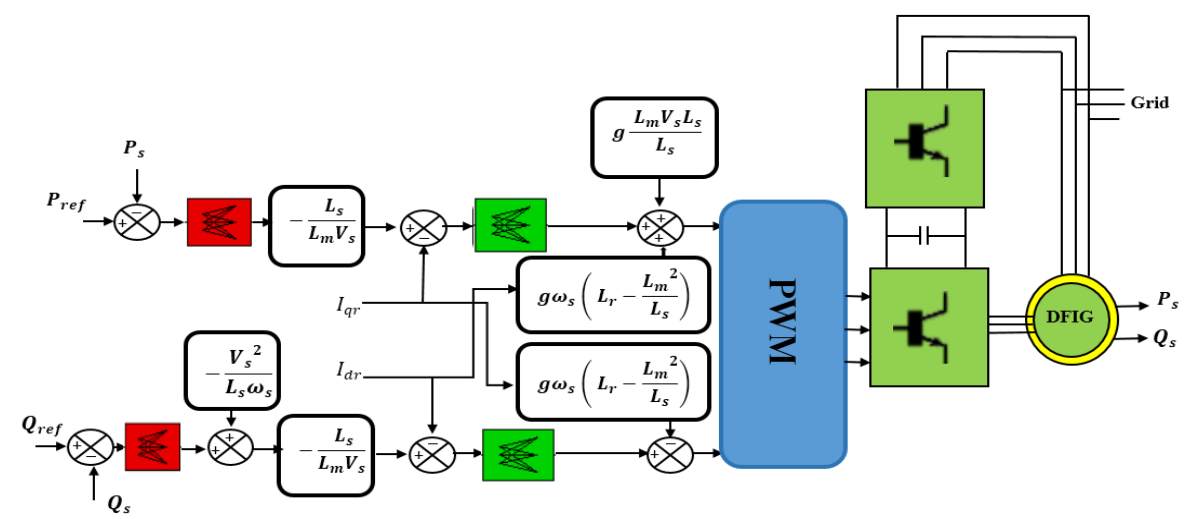

Figure 5. Global diagram of FOC control with neural network regulators

\section{SIMULATION RESULTS}

To prove the robustness and effectiveness of proposed control system, we apply the previous proposed controller to control of the deoubly-fed induction generator with wind energy conversion system. The generator and conversion system parameters are given in appendix. The configuration of the overall control system is shown in Fig.05. It mainly consists of a doubly-fed induction generator, a ramp comparison current-controlled pulse width modulated (PWM) inverter, an inverse park, a field oriented control and an outer power feedback control loops. Two different operating conditions are simulated, reference tracking and 
robustness against DFIG parameters variation, to illustrate the operation of the PI controller, RST controller and the proposed $\mathrm{NN}$ regulators.

\subsection{The reference tracking}

In this test, the simulation has been done with the rated parameters of the DFIM. This test consists of step changes in active and reactive powers in order to observe the system behavior with the proposed controller. The active and reactive power changes are made at $0.35 \mathrm{sec}$ and $0.45 \mathrm{sec}$, respectively.

The performance of wind energy conversion system with DFIG under this operating points test is shown in figure 6. This figure shows the active and reactive power responses for the PI, RST and NN controllers. The obtained results that are shown in figure 6 prove that the proposed controller has good performances in active and reactive power tracking. It is clearly observed that the oscillations decrease and the proposed NN controller present minimal rising time, no overshoot and negligible steady-state error compared to PI and RST regulators.
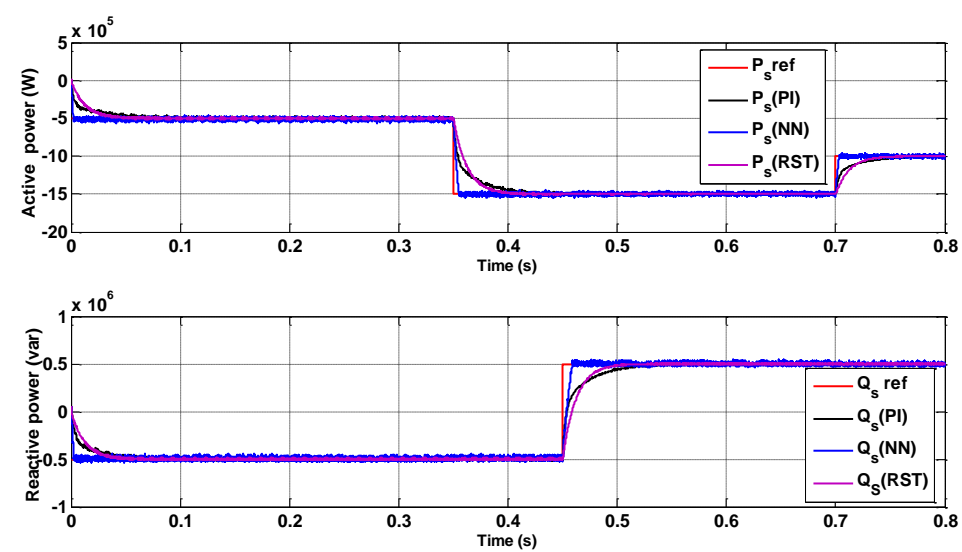

Figure 6. Simulation results for reference tracking using PI, RST and NN regulators.

\subsection{Robustness test aginst parameter variation}

The effectiveness of the proposed WECS with DFIG for the different controller has been tested under DFIG parameters variation. This second test consists of change on rated values of rotor resistance, stator inductance, rotor and mutual inductances. The applied variation rotor resistance is $50 \%$ of its nominal value whereas the stator and rotor inductance has been increased by $10 \%$ to their rated values. Finally, a decrease of $10 \%$ on the mutual inductance has been done.The performances of WECS with DFIG under this operating points test are depicted in figure 7-10. Figure 7 shows the simulation results of the system using the different controllers for rotor resistance variation. We notice here that the same reference of active and reactive power has taken for this test. From the simulation results, it is clearly observed that the system is not sensitive to this parameter variation and the NN controller shows good performance compared to another controller (PI and RST regulator). The performance of the system in the presence of the rotor and stator inductances are depicted in figure 8 and 9. Form the simulation results, it can be seen that the variation in rotor or stator inductances has an important effect on the control performance of WECS for the PI and RST regulators. However, the $\mathrm{NN}$ regulator presents the best performance in active and reactive responses compared to classical PI and RST regulators.

Finally, the dynamic responses of the wind energy conversion system equipped whit DFIG system under mutual inductance variation are illustrated in figure 10. The obtained results showed that mutual inductance has an important effect on the system responses for the classical regulators. However, the NN regulator can keep the same characteristics against this variation with a small effect on the rise time response. 

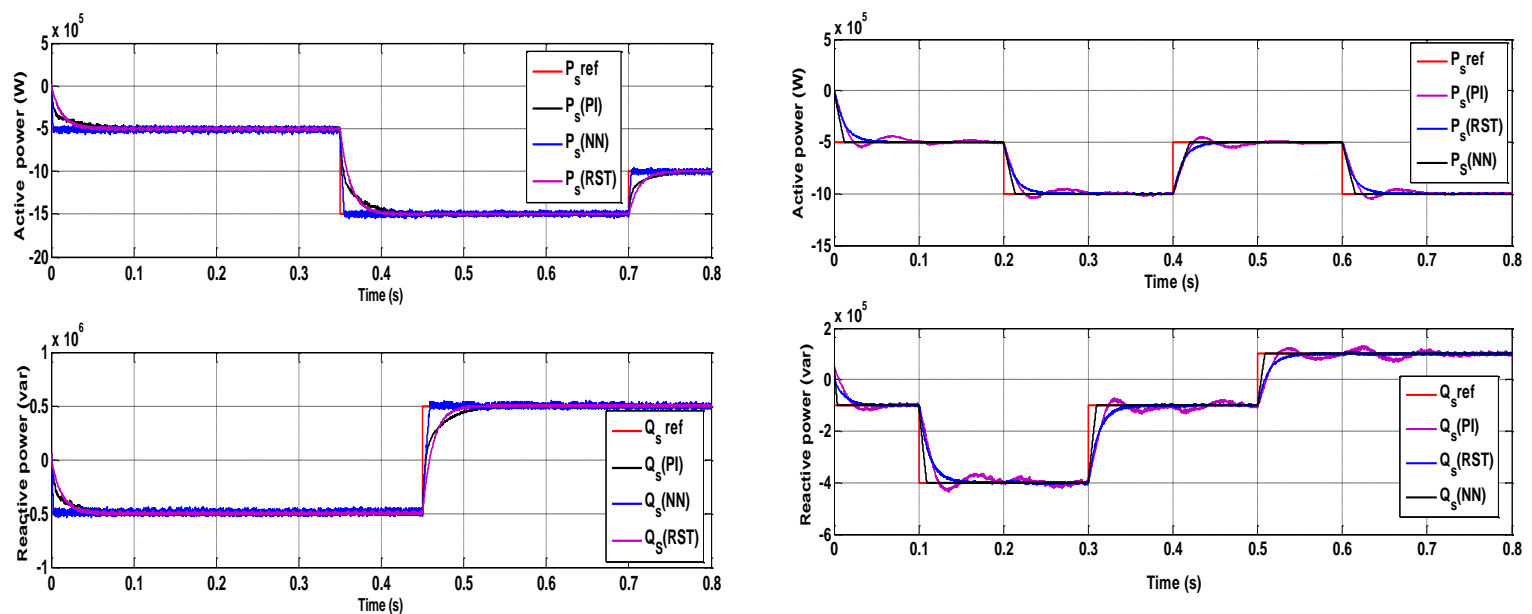

Figure 7. Simulation results for reference tracking using PI, RST and NN regulators with rotor resistance variation $(+50 \%)$

Figure 8. Simulation results for reference tracking using PI, RST and NN regulators with stator inductance variation $(+10 \%)$.
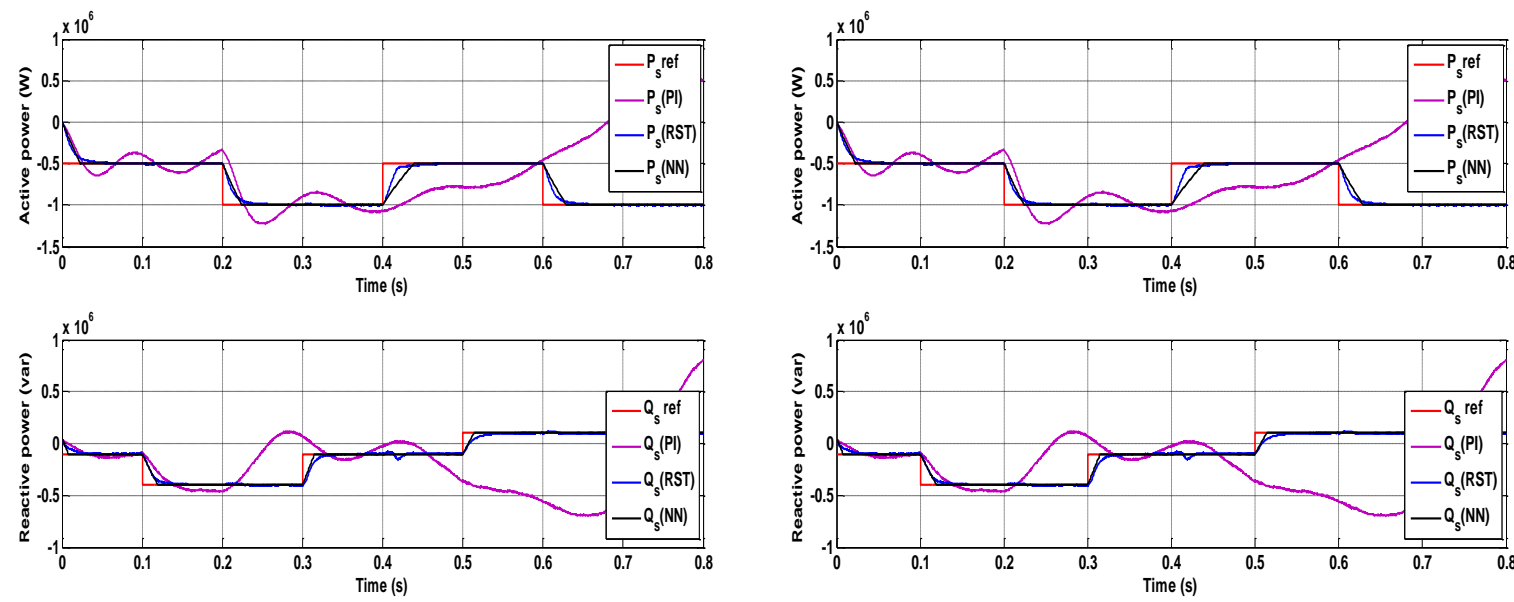

Figure 9. Simulation results for reference tracking using PI, RST and NN regulators with rotor inductance variation $(+10 \%)$

Figure 10. Simulation results for reference tracking using PI, RST and NN regulators with mutual inductance variation $(-10 \%)$

\section{CONCLUSION}

This paper presented a WECS based on DFIG. The studied device is composed of a DFIG with the rotor connected to the grid via a converter. The FOC of DFIG has been presented to regulate the active and reactive powers of the machine. The regulation is made with PI, RST regulators and with neural networks. The architecture of the neural network corrector retained is 1-3-1. It enabled us to improve the dynamic and static performances of the DFIG. Three different controllers are analyzed and compared. In the case of power reference tracking, the performances of the three controllers are almost similar but with a faster response time for the regulator neural network. A robustness test has also been investigated where the machine's parameters have been modified, the impact on the active and reactive powers values is important for PI controller whereas it is almost negligible for $\mathrm{NN}$ regulators.

\section{REFERENCES}

[1] T. Ackermann and L.Söder, "An overview of wind energy-status 2002," Renewable and Sustainable Energy Reviews, vol. 6, pp. 67-128, 2002.

[2] B. Belabbas et al., "Hybrid Fuzzy Sliding Mode Control of a DFIG Integrated into the Network," International Journal of Power Electronics and Drive System (IJPEDS) , vol. 3, pp. 351-364, December 2013. 
[3] B. Hopfensperger et al., "Stator-flux-oriented control of a doubly-fed induction machine with and without position encoder," Proceedings: Electric Power Applications, vol. 147, pp. 241-250, July 2000.

[4] N. Zerzouri and H. Labar, "Active and Reactive Power Control of a Doubly Fed Induction," International Journal of Power Electronics and Drive System, vol. 5, pp. 244-251, October 2014.

[5] F. Poitiers et al., "Control of a doubly-fed induction generator for wind energy conversion systems," IEEE Trans .Renewable Energy, vol. 3, pp. 373-378, December 2001.

[6] B. Hamane et al., "Direct active and reactive power control of DFIG based WECS using PI and sliding mode controllers," IECON Proceedings (Industrial Electronics Conference), no. 7048784, pp. 2050-2055, 2014.

[7] K. Viswanadha S Murthy et al., "A Performance Comparison of DFIG using Power Transfer," International Journal of Power Electronics and Drive System, vol. 5, pp. 176-184, October 2014.

[8] A. Giannakis et al., "A combined control strategy of a DFIG based on a sensorless power control through," Renewable Energy, pp. 30052-1, 2018.

[9] A. Mishra and P. Choudhary, "Artificial Neural Network Based Controller for Speed Control," International Journal of Power Electronics and Drive System (IJPEDS), vol. 2, pp. 402-408, December 2012.

[10] S. Laribi et al., "Impedance model for diagnosis of water management in fuelcell susing artificial neural networks methodology," international journal of hydrogen energ, vol. 41, pp. 17093-17101, 2016.

[11] F. Poitiers et al., "Advanced control of a doubly-fed induction generator for wind," Electric Power Systems Research, vol. 79, p. 1085-1096, 2009.

[12] N. Bouchiba et al., "Implementation and comparative study of control strategies for an isolated DFIG based WECS," The european phsical journal plus , pp. 132-415, 2017.

[13] B. Elnaghi et al., "Adaptation of PI controller used with combination of perturbationand observation method and feedback method for DFIG," Electrical Engineering, pp. 0565-8, 2017.

[14] B. HAMANE et al., "Comparative Study of PI, RST, Sliding Mode and Fuzzy Supervisory Controllers for DFIG based Wind Energy Conversion System," International Journal of Renewable Energy Research, vol. 5, pp. 11741184,2015

[15] T. Arantxa Tapia et al., "Modeling and control of a wind turbine driven doubly fed induction generator," IEEE Trans. on Energy Conversion, vol. 18, pp. 194-204, June 2003.

[16] Z. Boudjema et al., "A novel direct torque control using second order continuous sliding mode of adoubly fed induction generator for a wind energy conversion system," Turkish Journal of Electrical Engineering \& Computer Sciences, vol. 25, p. $965-975,2017$.

[17] M. Allam et al., "A comparative study between field oriented control and sliding mode control for dfig integrated in wind energy system," Journal of Electrical Engineering, vol. 15, pp. 205-213, 2015.

[18] S. Drid et al., "The Doubly Fed Induction Machine Modeling In The Separate Reference Frames," Journal of Electrical Engineering, vol. 4, pp. 11-16, 2004.

[19] J. J. François, "Les Réseaux de Neurones : Principes et Application," Hermès Sciences Publicat, sept $1994 .$.

[20] Song, Yong-Hua and Johns Allan T, "Application of fuzzy logic in power systems. Part 2. Comparison and integration with expert systems, neural networks and genetic algorithms," Power Engineering Journal, vol. 12, pp. 185-190, August 1998.

[21] W. Qiao et al., "Design of optimal PI controllers for doubly fed induction generators driven by wind turbines using particle swarm optimization," IEEE International Conference on Neural Networks - Conference Proceedings, pp. 1982-1987, 2006.

[22] J. Moré, "The Levenberg-Marquardt Algorithm: Implementation and Theory," Numerical Analysis, ed.G. A. Watson, Lecture Notes in Mathematics 630,Springer Verlag, pp. 105-116., 1977.

[23] M.T. Hagan and M. Menhaj, "Training feedforward networks with the Marquardt algorithm," IEEE Trans, Neural Networks, vol. 5, pp. 989-993, 1994.

\section{APPENDIX}

Table 1. Parameters of DFIM

\begin{tabular}{cc}
\hline Symbol & Value \\
\hline Rated Power PN & $1.5 \mathrm{MW}$ \\
Stator resistance Rs & $0.012 \boldsymbol{\Omega}$ \\
Rotor resistance Rr & $0.021 \boldsymbol{\Omega}$ \\
Stator inductance Ls & $0.0137 \mathrm{H}$ \\
Rotor inductance Lr & $0.0136 \mathrm{H}$ \\
Mutual inductance Lm 0 & $0.0135 \mathrm{H}$ \\
The friction coefficient fr & $0.0024 \mathrm{~N} . \mathrm{m} . \mathrm{s} 1$ \\
Slip g & 0.03 \\
Pole Pairs p & 2 \\
\hline
\end{tabular}

Table 2. Parameters of Turbine

\begin{tabular}{cc}
\hline Symbol & Value \\
\hline Radius of the wind & $35.25 \mathrm{~m}$ \\
turbine R & \\
Gear box G & 90 \\
inertia $\mathrm{J}$ & $1000 \mathrm{~kg} \cdot \mathrm{m}^{2}$ \\
Surface swept by & $\pi \cdot \mathrm{R}^{2} \mathrm{~m}^{2}$ \\
rotor $\mathrm{S}$ & \\
Air density $\rho$ & $1.22 \mathrm{~kg} / \mathrm{m}^{3}$ \\
\hline
\end{tabular}

Table 3. Parameters of Feed

\begin{tabular}{cl}
\hline Symbol & \multicolumn{1}{c}{ Value } \\
\hline Stator rated voltage & $398 / 690 \mathrm{~V}$ \\
$V s$ Rated & \\
Frequency stator $f$ & $50 \mathrm{~Hz}$ \\
Rotor rated voltage $V r$ & $225 / 389 \mathrm{~V}$ \\
Rated frequency & $14 \mathrm{~Hz}$ \\
stator $f_{2}$ & \\
\hline
\end{tabular}

